\begin{tabular}{c} 
Brazilian Journal \\
of Chemical \\
Engineering \\
\hline
\end{tabular}

ISSN 0104-6632

Printed in Brazil

www.abeq.org.br/bjche

Vol. 31, No. 03, pp. 643 - 648, July - September, 2014

dx.doi.org/10.1590/0104-6632.20140313s00003014

\title{
ANTIMICROBIAL ANALYSIS OF FILMS PROCESSED FROM CHITOSAN AND N,N,N-TRIMETHYLCHITOSAN
}

\author{
R. C. Goy and O. B. G. Assis ${ }^{*}$ \\ Embrapa Instrumentação, Rua XV de Novembro 1452, CEP: 13561-206 São Carlos - SP, Brazil. \\ Phone: + (55) (16) 2107-2800, Fax: + (55) (16) 2107-2902 \\ E-mail: odilio.assis@embrapa.br \\ (Submitted: October 8, 2013 ; Accepted: December 4, 2013)
}

\begin{abstract}
Chitosan and its derivatives have been proposed as bactericidal and fungicidal agents against a large numbers of gram-negative and gram-positive bacteria and fungi. Some antimicrobial mechanisms have been proposed for chitosan, with the most widely acceptable being the presence of charged- $\mathrm{NH}_{3}{ }^{+}$groups in the polymer backbone and its interactions with the bacterial wall constituents. Since this mechanism is based on an electrostatic interaction, it suggests that the greater the number of cationic amines, the higher will be the antimicrobial activity. So, in the present study, the effectiveness of commercial medium molecular weight chitosan and its ionic charged derivative (quaternized N,N,N-trimethylchitosan) were evaluated. Cast films of both materials were assessed against Staphylococcus aureus (gram-positive) and Escherichia coli (gramnegative) as model bacteria by inhibition zone formation. The results show positive activity against the grampositive microorganism for both materials. The antibacterial effectiveness of the chitosan derivative was dependent on the film polymer concentration. No activity however, was observed against the gram-negative species for either material in film form. The results point to the possibility of considering different antimicrobial mechanisms acting on each type of bacteria.
\end{abstract}

Keywords: Chitosan; N,N,N-trimethylchitosan; Bacterial activity; Biopolymers.

\section{INTRODUCTION}

Due to its ability to form gels and be transformed into films with controlled permeability and good mechanical properties, chitosan has been considered as a material with potential applications in several fields such as agriculture, food, medicine, textiles and water treatment. Chitosan, a deacetylated form of chitin, is a versatile copolymer formed by 2acetamido-2-deoxy-D-glucose and 2-amino-2-deoxyD-glucose (D-glucosamine) units linked by O-glycosidics $\beta$ (1-4) bonds. It is soluble in dilute aqueous acidic medium $(\mathrm{pH}<6.5)$ and has been evaluated in membrane form in systems for protein concentration (Mello et al., 2006); as a barrier for permeation of gases (Ito et al., 1997); for the purification of effluents from the dairy industry (Wanichpongpan et al., 2000) and for the improvement of blood compatibility in the hemodialysis process (Amiji, 1997), among other technical applications.

Chitosan also behaves as a good cation scavenger and has been used as an absorbing agent which forms chelate compounds, mainly with metals ions. In the presence of water the amino groups of chitosan can be protonated and the sorption of ionic species considerably improved (Guibal, 2004). Chitosan films have therefore been tested as membranes for the removal of heavy metals (Juang and Shiaua, 2000) and anionic dyes (Xu et al., 2008) from wastewater. The interaction with herbicides and other agricultural

*To whom correspondence should be addressed 
chemicals has also been encouraging (Assis and Britto, 2008), as well as the use of chitosan in the separation of ethanol (Uragami and Takigawa, 1990) and ethylene glycol (Nam and Lee, 1999) from water via pervaporation.

Chitosan also possesses many other useful features, including biocompatibility, biodegradability and remarkable antimicrobial properties (Rabea et al., 2003; Goy et al., 2009). Concerning the biocidal activity, the interaction between positively charged chitosan molecules and negatively charged microbial cell membranes is the most acceptable antimicrobial mechanism. In this model the interaction is mediated by the electrostatic forces between the chitosan protonated $\mathrm{NH}_{3}{ }^{+}$groups and the negative residues on the microorganism surface (Tsai and Su, 1999; Goy et al., 2009).

The salt form of chitosan, such as N,N,Ntrimethylchitosan (TMC), is particularly interesting for uses in antimicrobial applications since this derivative is characterized by having a higher density of permanent positive charges in the chain and, hence, a stronger electrostatic interaction with the microorganism's walls (Sadeghi et al., 2008; Silva et al., 2010). TMC can be obtained by the covalent addition of a substituent containing a quaternary ammonium group (Curti et al., 2003), or by an exhaustive methylation of the primary amine groups in the parent polymer (Britto and Assis, 2007a). TMC is soluble in a wide $\mathrm{pH}$ range and forms films with good mechanical properties (Britto and Assis, 2007b).

In this study the effectiveness of films cast from commercial chitosan and the derivative TMC against model gram-positive (Staphylococcus aureus) and gram-negative (Escherichia coli) bacteria, were assessed as a function of the polymer concentration, with focus on medical- and environmental-related applications.

\section{MATERIALS AND METHODS}

\section{Chemicals}

The starting chitosan was a medium molecular weight polymer purchased from Sigma-Aldrich Co. (St. Louis, MO, USA). For the methylation reaction, the basic sequence consisted of an initial suspension in the following proportion: $16 \mathrm{~mL}$ of dimethylsulfate (Synth, Brazil) and $4 \mathrm{~mL}$ of deionized water for each $1.0 \mathrm{~g}$ of chitosan $(0.005 \mathrm{~mol})$. Then $1.2 \mathrm{~g}$ of $\mathrm{NaOH}(0.015 \mathrm{~mol})$ and $0.88 \mathrm{~g}$ of $\mathrm{NaCl}(0.015 \mathrm{~mol})$ were added and the solution mixed.
The final product was obtained by precipitation with acetone. After rinsing, the derivative was filtered and vacuum dried. The extensive methylation of chitosan resulted in the derivative $\mathrm{N}, \mathrm{N}, \mathrm{N}-$ trimethylchitosan, by grafting methyl functionality onto the chitosan amine groups at the $\mathrm{C}-2$ position (Figure 1). Methylation details and a full characterization of the TMC structure can be found elsewhere (Britto and Assis, 2007a). Gels were prepared by dissolving commercial chitosan in $1 \%$ acetic acid in deionized water with constant stirring for 2 hours. The quaternized salt was directly dissolved in water and no plasticizer was used. Concentrations of 0.5 , 1.0, 2.0, 3.0, 4.0 and $5.0 \mathrm{~g} \mathrm{~L}^{-1}$ were prepared for both materials. Films were obtained by solution casting onto acrylic plates. Solvents were allowed to evaporate at room temperature $\left(25^{\circ} \mathrm{C} \pm 3\right)$ and, after drying, the films were peeled from the plate.

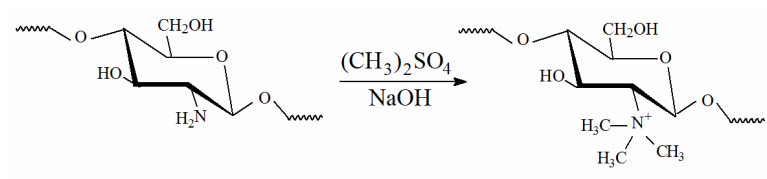

Figure 1: Schematic representation of the reaction leading to the quaternization of the amine groups of chitosan, resulting in N,N,N-trimethylchitosan.

\section{Antimicrobial Test}

The antibacterial activity was evaluated according to the zone of inhibition in the disc diffusion method (Barry et al., 1979). Petri dishes (9 $\mathrm{cm}$ in diameter) containing TSB (Tryptic Soy Broth) and agar medium were prepared and Escherichia coli (ATCC 8739) and Staphylococcus aureus (ATCC 25923) microorganisms were inoculated after appropriate dilution (both provided by Fundação Tropical André Tosello, Campinas, Brazil). Circular pieces of films approximately $1.5 \mathrm{~cm}$ in diameter were cut and placed on the surface of previously inoculated culture medium. The Petri dishes were stored at $32-37^{\circ} \mathrm{C}$ overnight inside a circulation oven to allow the bacteria to grow. Inhibition zones were measured on the basis of the average diameter of the clear zone directly on the dishes. All experiments were repeated four times, counting a total of 12 samples assayed for each material.

\section{RESULTS AND DISCUSSION}

Figure 2 shows as example of the antimicrobial activities against $S$. aureus and E. coli by formation 
of a zone of inhibition around film samples of chitosan and TMC, processed at a polymer concentration of $2.0 \mathrm{gL}^{-1}$. Both materials appear to be highly effective against $\mathrm{S}$. aureus growth (well-defined zone of inhibition), but no activity was observed against the gram-negative (E. coli) species (no zone responses), as seen in Figures $2 \mathrm{c}$ and 2d. By comparing the inhibition halos, wider diameters were measured for TMC films, resulting in an expected better antimicrobial activity of this material. Numerical data expressed as a function of polymer concentration is graphically shown in Figure 3.

Concerning the activity against S.aureus, despite the higher performance of TMC, both materials behaved similarly, whereas the concentration appears to have a non-linear effect on the activity. In fact, a peak of maximum activity is clearly suggested for films processed with small amounts of polymer (concentrations around 1.5-2.0 $\mathrm{gL}^{-1}$ ) followed by stabilization or even a tendency to a reduction in the diameter of the zone as the polymer concentration increases (Figure 3).

The results imply that a higher concentration of chitosan in the film formation does not necessarily mean an increase in the antimicrobial efficiency; as measured via the zone of inhibition, it otherwise resulted in a slight reduction in the overall activity. This can be understood in terms of the spatial arrangement of the polymer chains. Low polymer concentration results in a relatively small number of chains interacting with each other, so the charged sites available for external coupling are maximized (Palermo and Kuroda, 2010). Gabriel et al., (2009), additionally states that less chain-chain bonding results in an increased flexibility of the active moieties positioned on opposite sides of the polymer backbone, favoring interfacial interactions. As the concentration increases during solvent evaporation, the formation of cross-linking, hydrogen and covalent bonds amongst the functional groups of the chains is favored and the polymer structure tends to assume a highly coiled and dense configuration. This in turn imposes spatial restrictions to functional group-medium interactions (Solomonidou et al., 2011). Consequently, fewer charged sites will be available to bind to bacterial cell walls. At high polymer concentration, the solvent plays a fundamental role since the formation of clusters by entangled molecules may occur while in solution (Curti et al., 2003). In particular, for polyelectrolytes such as chitosan it is energetically favorable to establish electrostatic interactions between chains, leading to a stabilized ionic network (interchain coupling).
Such a configuration can affect interactions within the surroundings (Springborg, 1989).
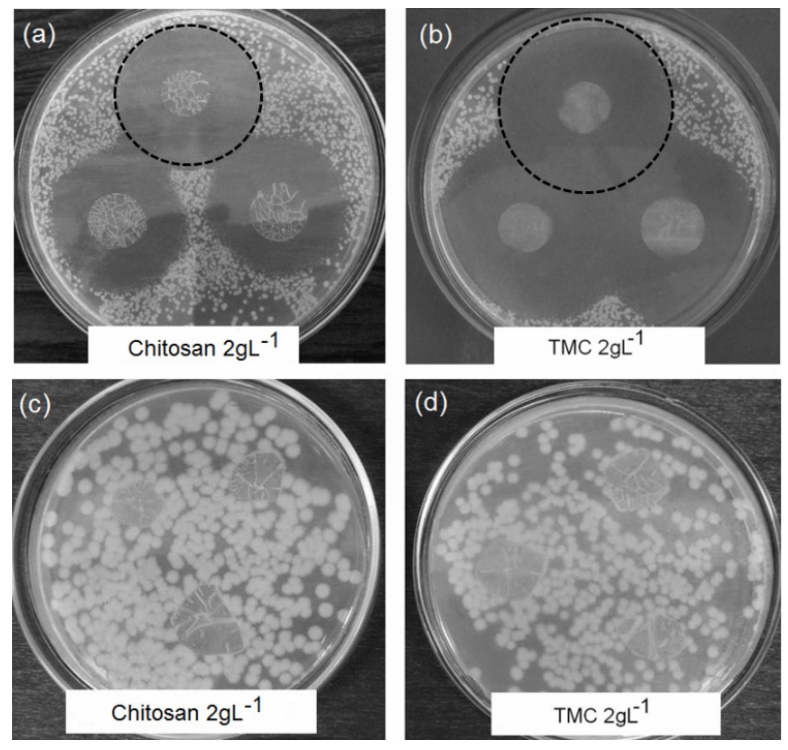

Figure 2: Examples of the inhibitory effect of chitosan and TMC $\left(2.0 \mathrm{gL}^{-1}\right)$ films against gram-positive bacteria S. aureus, (a) and (b), and gram-negative E. coli, (c) and (d).

Comparing materials, the antibacterial activity of commercial chitosan was inferior to that measured for TMC in all tested concentrations, in agreement with previous reports in the literature (Sadeghi et al., 2008; Goy et al., 2009). The main difference between the parent chitosan and TMC is the density of charges and these results reassert the role of the electrostatic interaction as a determining mechanism in polymer antibacterial activity. Commercial chitosan has an intrinsic pKa value around 6.5 and only approximately $24 \%$ of its primary amine groups are positively charged in acid medium, whereas all primary and quaternized amine groups of TMC are protonated, even in neutral solution (Mao et al., 2006). According to the literature, the electrostatic interaction between the polysaccharide chains and the surface of the microorganism creates a two-fold interference. These are: i) to promote changes in the membrane cell permeability, thus provoking internal osmotic imbalances; this in turn inhibits microorganism growth (Shahidi et al., 1999); ii) a peptidoglycan hydrolysis in the microorganism wall, leading to the leakage of intracellular electrolytes. These may include potassium ions and others lowmolecular weight proteinaceous constituents (e.g. proteins, nucleic acids, glucose, and lactate dehydrogenase). This causes the microorganism to perish (Chen et al., 1998; Devlieghere et al., 2004). 


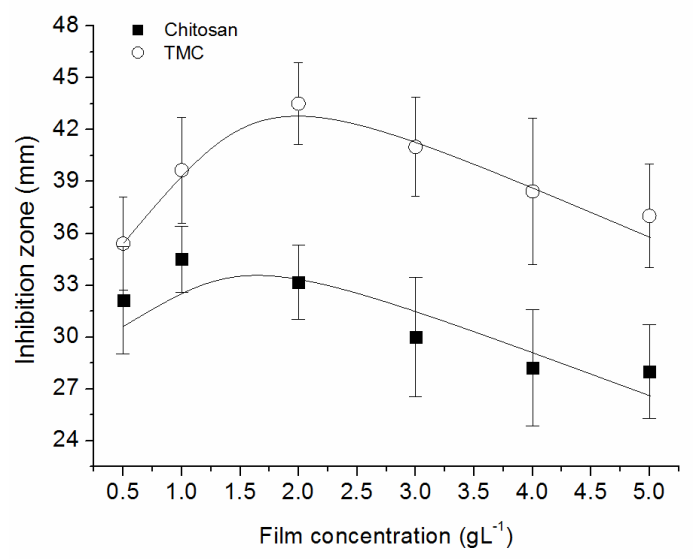

Figure 3: Inhibition zone as a function of the film concentration, as measured against the bacteria $S$. aureus.

Since no activity was observed in the solid state (film format) for the gram-negative E. coli, the effects of chitosan might differ for the two kinds of bacteria. Generally, when in solution, the intensity of chitosan antimicrobial activity is considered in terms of its $\mathrm{pKa}, \mathrm{pH}$, concentration, molecular weight and degree of deacetylation. Several works have reported that chitosan does have good antimicrobial activity when dispersed in acidic aqueous solution, against both gram-positive than gram-negative bacteria. Most of these studies, however, point to a comparatively superior activity against the gram-positive species (Sudarshan et al., 1992; Tsai et al., 1999; Zhong et al., 2008).

Such susceptibility could be attributed to bacterial membrane characteristics: gram-positive microorganisms have an outer cell wall composed of acidic polysaccharides (teichoic acids) and peptidoglycan with plenty of pores, which promotes foreign molecule adhesion or entry into the cell (Kong et al., 2010). In gram-negative bacteria, the cell wall is made up of a pair of membranes, an outer membrane consisting of lipopolysaccharide (LPS), lipids and proteins, and an internal peptidoglycan cytoplasmic membrane. In such a bilayer structure, the outer membrane has high molecular weight and acts as a barrier against foreign molecules. Furthermore, according to Kong et al. (2010), the composition of the gram-negative bacteria outer membrane provides the bacterium with a hydrophilic surface, an important factor for short-range interactions via hydrophilic forces causing strong attachments.

Conversely, in gram-positive species, surface models state that, in the outer wall charges predominate in the N-terminal ends with dispersed hydrophobic domains (Navarre et al., 1999). Such a con- figuration of hydrophobic domains and charged tails results in defined sites suitable for polymer incorporation onto the surface. This facilitates a proteolytic cleavage or entry into the cells, which can inhibit or destroy cellular functions (Schneewind and MihaylovaPetkov, 1993).

Such models shed light on why, when in aqueous solution, both chitosan and the charged derivative TMC result in good activities against gram positive and gram negative bacteria (Zheng and Zhu, 2003; Sang-Hoon and Hudson, 2004). When dispersed in dilute solution the polymer chains are expected to have mobility and flexibility, being free to interact either by hydrophilic/hydrophobic forces or by ionic attraction, giving a greater antimicrobial activity than when measured in film form.

\section{CONCLUSION}

Commercial medium molecular weight chitosan and its quaternized derivative N,N,N-trimethylchitosan, when processed in film form, both showed effective antimicrobial activity against gram-positive bacteria ( $S$. aureus). The activity of the chitosan derivative was found to be superior, according to measurements based on the inhibition zone in nutrient medium. The polymer concentration used in film processing also had an effect on the activity. No antimicrobial activity was found against the gramnegative bacterium tested (E. coli), suggesting that different species behave differently to the chitosan contact. This result differs from the literature where an acidic solutions of chitosan and its derivatives do have activities against both bacteria, though in different intensities. The present study serves to demonstrate that chitosan in solid form (as film or membrane) can be effectively used as an antimicrobial material in food, environmental or medical areas especially against gram-positive bacteria.

\section{ACKNOWLEDGEMENT}

This work was supported by FAPESP, CNPq and Embrapa (Rede AgroNano).

\section{REFERENCES}

Amiji, M. M., Surface modification of chitosan membranes by complexation-interpenetration of anionic polysaccharides for improved blood compatibility in hemodialysis. Journal of Biomaterials 
Science, Polymer Edition, 8(4), 281-298 (1997).

Assis, O. B. G. and Britto, D., Formed-in-place polyelectrolyte complex membranes for atrazine recovery from aqueous media. Journal of Polymers and the Environment, 16(3), 192-197 (2008).

Barry, A. L., Coyle, M. B., Thornsberry, C., Gerlach, E. H. and Hawkinson, R. W., Methods of measuring zones of inhibition with the Bauer-Kirby disk susceptibility test. Journal of Clinical Microbiology, 10(6), 885-889 (1979).

Britto, D. and Assis, O. B. G., A novel method for obtaining a quaternary salt of chitosan. Carbohydrate Polymers, 69(2), 305-310 (2007a).

Britto, D. and Assis, O. B. G., Synthesis and mechanical properties of quaternary salts of chitosan-based films for food application. International Journal of Biological Macromolecules, 41(2), 198-203 (2007b).

Chen, C. S., Liau, W. Y. and Tsai, G. J., Antibacterial effects of $\mathrm{N}$-sulfonated and $\mathrm{N}$-sulfobenzoyl chitosan and application to oyster preservation. Journal of Food Protection, 61(9), 1124-1128 (1998).

Curti, E., Britto, D. and Campana-Filho, S. P., Methylation of chitosan with iodomethane: Effect of reaction conditions on chemoselectivity and degree of substitution. Macromolecular Bioscience, 3(10), 571-576, 2003 (2003).

Devlieghere, F., Vermeulen, A. and Debevere, J., Chitosan: Antimicrobial activity, interactions with food components and applicability as a coating on fruit and vegetables. Food Microbiology, 21(6), 703-714 (2004).

Gabriel, G. J., Maegerlein, J. A., Nelson, C. F., Dabkowski, J. M., Eren, T., Nüsslein, K. and Tew, G. N., Comparison of facially amphiphilic versus segregated monomers in the design of antibacterial copolymers. Chemistry - A European Journal, 15(2), 433-439 (2009).

Goy, R. C., Britto, D. and Assis, O. B. G., A review of the antimicrobial activity of chitosan. Polímeros: Ciência e Tecnologia, 19(3), 241-247 (2009).

Guibal, E., Interactions of metal ions with chitosanbased sorbents: A review. Separation and Purification Technology, 38(1), 43-74 (2004).

Ito, A., Sato, M. and Anma, T., Permeability of $\mathrm{CO}_{2}$ through chitosan membrane swollen by water vapor in feed gas. Die Angewandte Makromolekulare Chemie, 248(1), 85-94 (1997).

Juang, R-S. and Shiaua, R-C., Dispersion-free membrane extraction: Case studies of metal ion and organic acid extraction. Journal of Membrane Science, 165(1), 59-73 (2000).
Kong, M., Chen, X. G., Xing, K. and Park, H. J., Antimicrobial properties of chitosan and mode of action: A state of the art review. International Journal of Food Microbiology, 144(1), 51-63 (2010).

Mao, S., Bakowsky, U., Jintapattanakit, A. and Kissel, T., Self-assembled polyelectrolyte nanocomplexes between chitosan derivatives and insulin. Journal of Pharmaceutical Sciences, 95(5) 1035-1048 (2006).

Mello, R. S., Bedendo, G. C., Nome, F., Fiedler, H. D. and Laranjeira, M. C. M., Preparation of chitosan membranes for filtration and concentration of compounds under high pressure process. Polymer Bulletin, 56(4-5), 447-454 (2006).

Nam, S. Y. and Lee, Y. M., Pervaporation of ethylene glycol-water mixtures: I. Pervaporation performance of surface crosslinked chitosan membranes. Journal of Membrane Science, 153(2), 155-162 (1999).

Navarre, W. W. and Schneewind, O., Surface proteins of gram-positive bacteria and mechanisms of their targeting to the cell wall envelope. Microbiology and Molecular Biology Reviews, 63(1), 174-229 (1999).

Palermo, E. F. and Kuroda, K., Structural determinants of antimicrobial activity in polymers which mimic host defense peptides. Applied Microbiology Biotechnology, 87(6), 1605-1615 (2010).

Rabea, E. I., Badawy, M. E. T., Stevens, C., Smagghe, G. and Steurbaut, W., Chitosan as antimicrobial agent: Applications and mode of action. Biomacromoles, 4(6), 1457-1465 (2003).

Sadeghi, A. M. M., Amini, M., Avadi, M. R., Siedi, F., Rafiee-Tehrani. M. and Junginger, H. E., Synthesis, characterization, and antibacterial effects of trimethylated and triethylated 6-NH2-6deoxy chitosan. Journal of Bioactive and Compatible Polymers, 23(3), 262-275 (2008).

Sang-Hoon, L. and Hudson, S. M., Synthesis and antimicrobial activity of a water-soluble chitosan derivative with a fiber-reactive group. Carbohydrate Research, 339(2), 313-319 (2004).

Schneewind, O., Mihaylova-Petkov, D. and Model, P., Cell wall sorting signals in surface proteins of Gram-positive bacteria. The EMBO Journal, 12 (12), 4803-4811 (1993).

Shahidi, F., Arachchi, J. and Jeon, Y-J., Food applications of chitin and chitosans. Trends in Food Science \& Technology, 10(2), 37-51 (1999).

Silva, L. P., Britto, D., Seleghim, M. H. R. and Assis, O. B. G., In vitro activity of water-soluble quaternary chitosan chloride salt against E. coli. World Journal of Microbiology and Biotechnology, 26(11), 2089-2092 (2010). 
Solomonidou, D., Cremer, K., Krumme, M. and Kreuter, J., Effect of carbomer concentration and degree of neutralization on the mucoadhesive properties of polymer films. Journal of Biomaterials Science, Polymer Edition, 12(11), 1191-1205 (2001).

Springborg, M., Interactions between two identical polymer chains studied with first-principle calculations. Physic Review, B, 40(8), 5774-5779 (1989).

Sudarshan, N. R., Hoover, D. G. and Knorr, D., Antibacterial action of chitosan. Food Biotechnology, 6(3), 257-272 (1992).

Tsai, G. J. and Su W. H., Antibacterial activity of shrimp chitosan against Escherichia coli. Journal of Food Protection, 62(3), 239-243 (1999).

Uragami, T. and Takigawa, T., Permeation and separation characteristics of ethanol-water mixtures through chitosan derivative membranes by per- vaporation and evapomeation. Polymer, 31(4), 668-672 (1990).

Wanichpongpan, P., Annachhatre, A. P. and Chandrkrachang, S., Ultrafiltration of cheese whey using chitosan membrane. Journal Metals, Materials and Minerals, 10(1), 61-75 (2000).

$\mathrm{Xu}, \mathrm{D}$., Hein, S. and Wang, K., Chitosan membrane in separation applications. Materials Science and Technology, 24(9), 1076-1087 (2008).

Zheng, L.-Y. and Zhu, J.-F., Study on antimicrobial activity of chitosan with different molecular weights. Carbohydrate Polymers, 54(1), 527-630 (2003).

Zhong, Z. M., Xing, R. G., Liu, S., Wang, L., Cai, S. B. and Li, P. C., Synthesis of a cylthiourea derivatives of chitosan and their antimicrobial activities in vitro. Carbohydrate Research, 343(3), 566-570 (2008). 